\title{
Analysis of Design Directions for Unmanned Surface Vehicles (USVs)
}

\author{
Jinyeong Heo', Junghoon Kim², Yongjin Kwon ${ }^{1 *}$ \\ ${ }^{1}$ Department of Industrial Engineering, Ajou University, Suwon, South Korea \\ ${ }^{2}$ The $6{ }^{\text {th }}$ R\&D Institute, Agency for Defense Development, Jinhae, South Korea \\ Email:*yk73@ajou.ac.kr
}

How to cite this paper: Heo, J., Kim, J. and Kwon, Y.J. (2017) Analysis of Design Directions for Unmanned Surface Vehicles (USVs). Journal of Computer and Communications, 5, 92-100. https://doi.org/10.4236/jcc.2017.57010

Received: April 17, 2017

Accepted: May 19, 2017

Published: May 22, 2017

Copyright ( 92017 by authors and Scientific Research Publishing Inc. This work is licensed under the Creative Commons Attribution International License (CC BY 4.0).

http://creativecommons.org/licenses/by/4.0/

\section{(c) (i) Open Access}

\begin{abstract}
In recent years, because of the development of marine military science technology, there is a growing interest in the unmanned systems throughout the world. Also, the demand of Unmanned Surface Vehicles (USVs) which can be autonomously operated without the operator intervention is increasing dramatically. The growing interests lie in the facts that those USVs can be manufactured at much lower costs, and can be operated without the human fatigue, while can be sent to the hostile or quite dangerous areas that are inherently unhealthy for human operators. The utilization and the deployment of such vessels will continue to grow in the future. In this paper, along with the technological development of unmanned surface vehicles, we investigate and analyze the cases of already developed platforms and identify the trends of the technological advances. Additionally, we suggest the future directions of development.
\end{abstract}

\section{Keywords}

Maritime Military System, Unmanned System, USV (Unmanned Surface Vehicle), USV Operation Function, Autonomous Control

\section{Introduction}

In marine environments, autonomous USVs are increasingly deployed to the missions that require a very long patrol time in dangerous areas. It is very advantageous to utilize such unmanned system due to the facts that those vessels are being operated without humans onboard, while the vessels can be manufactured at a considerably lower cost. Because of those inherent benefits of unmanned systems, there has been a steadily growing interest all around the world [1] [2]. In recent years, the military USVs have been actively developed around the world and major missions are being expanded not only for marine research 
but also for military purposes such as target tracking, surveillance, reconnaissance, mine sweeping, and anti-submarine warfare [3]. In many ways, the USVs are very different from the manned counterparts. The manned vehicles are constantly monitored and stationed by the operators, who actually feel and sense the surroundings and the workings of the vehicles. Therefore, the manned systems have no problem in terms of responding to the changing situations [4] [5]. In this regards, the control of the manned vehicles can be instantaneous and immediate. However, the unmanned vehicles (USVs) are completely different [6]. The USVs are remotely operated without any human operators onboard. This means that any changes in the surroundings of USVs must be sensed by the onboard sensing devices, and electronically transmitted to the remotely situated human operators. The human operators, in turn, monitor the sensor signals, and internally construct the 3D images of what the USVs are facing. The sensitivity of the sensing devices and how the sensed information is graphically presented to the human operators can greatly influence the way in which the remote vehicles are responding to the changing environments [6] [7]. Therefore, the USV itself and the ground control station (GCS) where the remotely situated human operators are controlling the USV have to be concurrently designed and considered in terms of how to reach the intended functions and performance levels for the USVs [8]. In this regards, according to our initial study, the majority of the USVs that have been developed by many nations resemble each other as to the vehicle shape, the operating methods, and the missions that are being carried out [9] [10]. The purpose of this paper is, therefore, to investigate the recently technological development of USVs and identify the concept of USV operations. Such analysis has not been properly addressed, hence the study results will provide good insights towards the development of the USVs in the complex marine environment [9] [10] [11] [12] [13].

\section{Review of Recent Development}

The main differences between the USVs and the manned surface vehicles include the following. 1) The overall mechanical workings of both vehicles are almost identical. However, the USVs must have onboard communication devices that can constantly transmit the various signals (i.e., system status data and sensor signals) to the GCS. 2) The USVs must have a ground control station for remote operations. 3) Most recent USVs are equipped with intelligent and autonomous functions for navigation and mission execution. The main missions that can be performed by USVs in military are classified into intelligence, surveillance and reconnaissance (ISR), mine countermeasure (MCM), anti-submarine warfare (ASW), special operations support, rescue operations, and electronic warfare [14]. In fact, the application areas are increasing every year, and the trend will continue in the foreseeable future. In this paper, we classified development cases based on ISR, MCM, ASW missions. We analyzed most countries, which include USA, Israel, Singapore, and other countries that are actively developing advanced marine unmanned vehicle systems. We identified the trends 
of the technological advances, while suggesting the future directions for development.

\subsection{United States of America}

Anaconda 2.0 USV

- USSOCOM is developing Anaconda 2.0 USV for marine control and counter-terrorism operations and so on. The Anaconda 1.0 is operated by remote control in the zone without obstacles, and the Anaconda 2.0, a fully autonomous USV which has the artificial intelligence is capable of quicker and more complex maneuvering.

ACTUV (Anti-Submarine Warfare Continuous Trail Unmanned Vessel)

- ACTUV is a diesel USV developed for automatic tracking of submarines by DARPA. ACTUV not only keeps track of the submarines detected by its sonar sensors but also can share information with other unmanned vehicles.

- Analysis between Anaconda and ACTUV

- Both platforms in Table 1 represent the currently most advanced unmanned USVs from the USA [15] [16]. The mission planning systems and the autonomy levels represent the highest sophistication among the competitors. In its current form, both are still under development and a various set of tests is undertaking. When they are actually deployed, they will be reaching near $100 \%$ automated mission carryout capabilities. Anaconda will also be used by Special Forces.

- CUSV (Common Unmanned Surface Vehicle)

- CUSV is a maritime security system of the US Navy and is a fleet-class unmanned surface vehicle. In addition, CUSV is a stand-alone littoral combat ship that is used for reconnaissance surveillance, torpedo detection, and asymmetric operations and so on. It also includes a side scan sonar, a minesweeper module, and a non-lethal weapon system.

Table 1. Anaconda 2.0 and ACTUV.

\begin{tabular}{|c|c|c|c|c|}
\hline Model & \multicolumn{2}{|c|}{ Anaconda 2.0} & \multicolumn{2}{|c|}{ ACTUV } \\
\hline \multicolumn{5}{|l|}{ Figure } \\
\hline \multirow{5}{*}{ Spec } & Length & $10 \mathrm{~m}$ & Length & $40 \mathrm{~m}$ \\
\hline & Weight & - & Weight & 40 tons \\
\hline & Velocity & $50 \mathrm{kts}$ & Velocity & - \\
\hline & Engine & Diesel & Engine & - \\
\hline & Operation Time & $8 \mathrm{hr}$ & Operation Time & - \\
\hline Main Mission & \multicolumn{2}{|c|}{ ISR, MCM, ASW } & \multicolumn{2}{|c|}{ ISR } \\
\hline Manufacturer & \multicolumn{2}{|c|}{ Swiftships } & \multicolumn{2}{|c|}{ DARPA } \\
\hline
\end{tabular}




\section{ASW USV}

- ASW USV is a fleet-class USV for anti-submarine warfare. It was built on the basis of an open type, high-speed rigid-hull inflatable boat (RHIB) technology, which can be operated remotely and can mount the anti-submarine mission equipment (that is, unmanned dipping sonar). The core subsystem includes a surface search radar and an enhanced communications system.

- Analysis between CUSV and ASW

- Both platforms in Table 2 look similar in terms of hull shapes [17] [18]. However, the ASW is much larger and much heavier than the CUSV. ASW is designed to stay afloat for a very long time, because its main mission is to loiter, find, and detect the enemy submarines. Therefore, its hull size has to be enlarged, not only it has to carry much fuel, but also it has to withstand rough seas. CUSV on the other hand is used for coast patrol around the shallow sea areas, hence its size is much smaller and lightweight.

\subsection{Other Nations}

- KATANA (Israel)

- KATANA in Table 3 is an unmanned surface vehicle developed by the Israel Aerospace Industries (IAI) [19]. Its main mission is coastal and port security. Also, it is equipped with the remote control system and non-lethal weapons and can be operated at sea state from 4 to 6 .

- PROTECTOR (Israel)

- PROTECTOR in Table 3 is currently being operated by Israel Navy for the coastal reconnaissance and harbor security, minesweeping, and enemy submarine detection [20]. Also, it can shoot the guns by the remote control system because it is equipped with a Mini Typhoon.

Analysis between KATANA and PROTECTOR

Table 2. CUSV and ASW USV.

\begin{tabular}{|c|c|c|c|c|}
\hline Model & \multicolumn{2}{|c|}{ CUSV } & \multicolumn{2}{|c|}{ ASW USV } \\
\hline \multirow[t]{3}{*}{ Figure } & & & & \\
\hline & Length & $4.2 \mathrm{~m}$ & Length & $11 \mathrm{~m}$ \\
\hline & Width & $1.8 \mathrm{~m}$ & Weight & $7700 \mathrm{~kg}$ \\
\hline \multirow[t]{3}{*}{ Spec } & Velocity & $28 \mathrm{kts}$ & Velocity & $35 \mathrm{kts}$ \\
\hline & Operation Range & $1200 \mathrm{~nm}$ & Engine & - \\
\hline & Operation Time & $24 \mathrm{hr}$ & Operation Time & $24 \mathrm{hr}$ \\
\hline Main Mission & \multicolumn{2}{|c|}{ ISR, MCM, ASW } & \multicolumn{2}{|c|}{ ASW } \\
\hline Manufacturer & \multicolumn{2}{|c|}{$\begin{array}{c}\text { Textron Systems, AAI Unmanned } \\
\text { Aircraft Systems }\end{array}$} & \multicolumn{2}{|c|}{ General Dynamics Robotics Systems } \\
\hline
\end{tabular}


Table 3. KATANA and Protector.

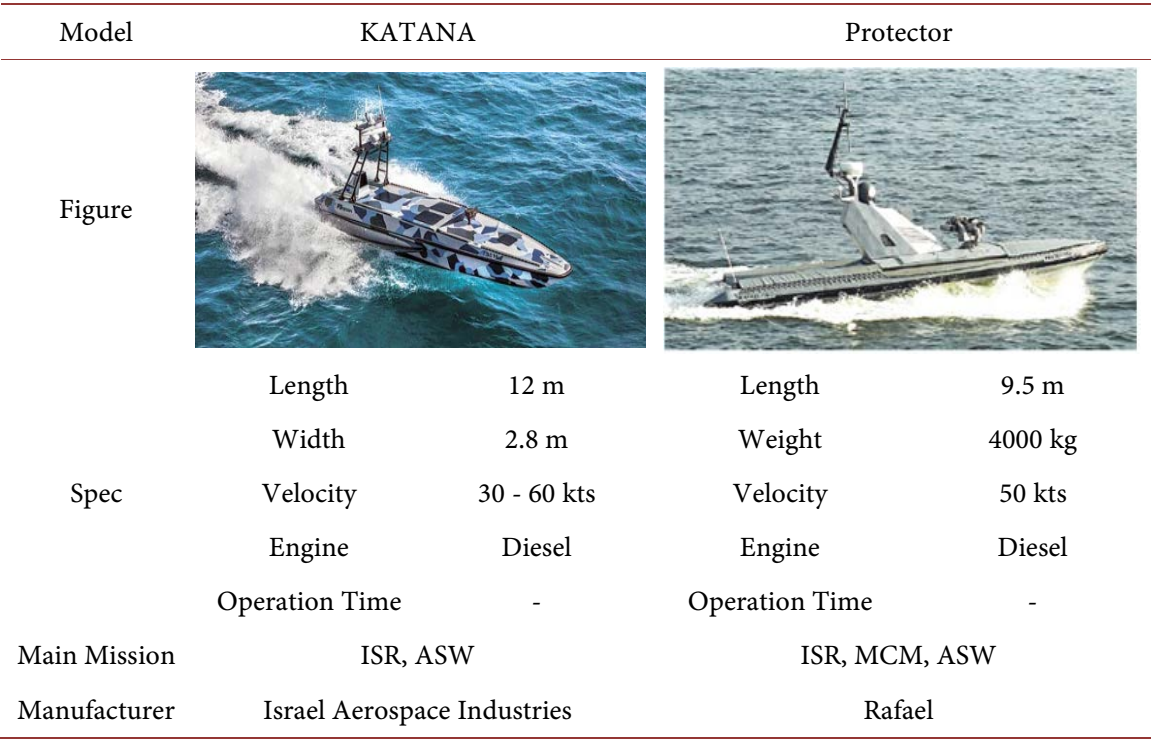

- Protector is the predecessor of the Katana, and smaller in terms of size. Protector is the Israel's first unmanned USV that has been actually deployed and even exported to the USA. Protector, however, is controlled remotely and there is not much automated or intelligent mission carryout capabilities. All tasks must be watched and controlled by the remote operators. Even Katana is the more recent development, its autonomy levels have not been publically announced yet.

- Silver Marlin (Israel)

- Silver marlin is equipped with equipment such as day and night surveillance, obstacle avoidance sensor, remote control shooting system. It was developed in 2007 for coastal reconnaissance, harbor security, minesweeping, and combat purposes. It has been operated by Israel Navy since November 2009 .

- Vigilant (Singapore)

- Vigilant completed its development in September 2013 by Zycraft and is an USV of stand-alone type capable of carrying out various missions, such as coastal monitoring mission, rescue mission, special mission, and others. It can perform a wide range of operations over a long period of time

Analysis between Silver Marlin and Vigilant

- Both platforms in Table 4 are quite similar in terms of the types of mission they are carrying [21] [22]. In terms of size, Vigilant is much bigger and it is claimed that it can stay in the sea for about 30 days. Since Singapore puts great emphasis on the safety of its fleet operations and the security of its surrounding seas, the purpose of Vigilant is rather clear. Both are operated by remotely situated operators. In addition, the autonomy levels are not yet disclosed.

- Venus 16 (Singapore)

- The superstructure of Venus 16 in Table 5 is modular and there are three derived types with $9 \mathrm{~m}, 11 \mathrm{~m}$, and $16 \mathrm{~m}$ in length [23]. Also, a remote weapon 
station (OtoMelara) for defending the fleet, Thales's synthetic aperture sonar (T-SAS) and ECA group's K-STER expendable mine disposal system (EMDS) for mine countermeasures (MCM) are known to be integrated.

- Inspector MK2 Extended (France)

- Inspector MK2 Extendedon Table 5 is a multipurpose platform that allows autonomous and remote control and real-time obstacle and target detection capabilities [24]. Also, it can perform maritime block operations and is capable of situational awareness.

- Analysis between Venus 16 and Inspector MK2 Extended

Table 4. Silver marlin and vigilant.

\begin{tabular}{|c|c|c|c|c|}
\hline Model & \multicolumn{2}{|c|}{ Silver Marlin } & \multicolumn{2}{|c|}{ Vigilant } \\
\hline \multicolumn{5}{|l|}{ Figure } \\
\hline \multirow{5}{*}{ Spec } & Length & $10.67 \mathrm{~m}$ & Length & $16.5 \mathrm{~m}$ \\
\hline & Weight & $4000 \mathrm{~kg}$ & Weight & $6000 \mathrm{~kg}$ \\
\hline & Velocity & $45 \mathrm{kts}$ & Velocity & $12-30 \mathrm{kts}$ \\
\hline & Engine & Diesel & Engine & Diesel \\
\hline & Operation Time & $24-36 \mathrm{hr}$ & Operation Time & 30 days \\
\hline Main Mission & \multicolumn{2}{|c|}{ ISR, MCM, ASW } & \multicolumn{2}{|c|}{ ISR, ASW } \\
\hline Manufacturer & \multicolumn{2}{|c|}{ Elbit Systems } & \multicolumn{2}{|c|}{ Zycraft } \\
\hline
\end{tabular}

Table 5. Venus 16 and INSPECTOR MK2 EXTEND.

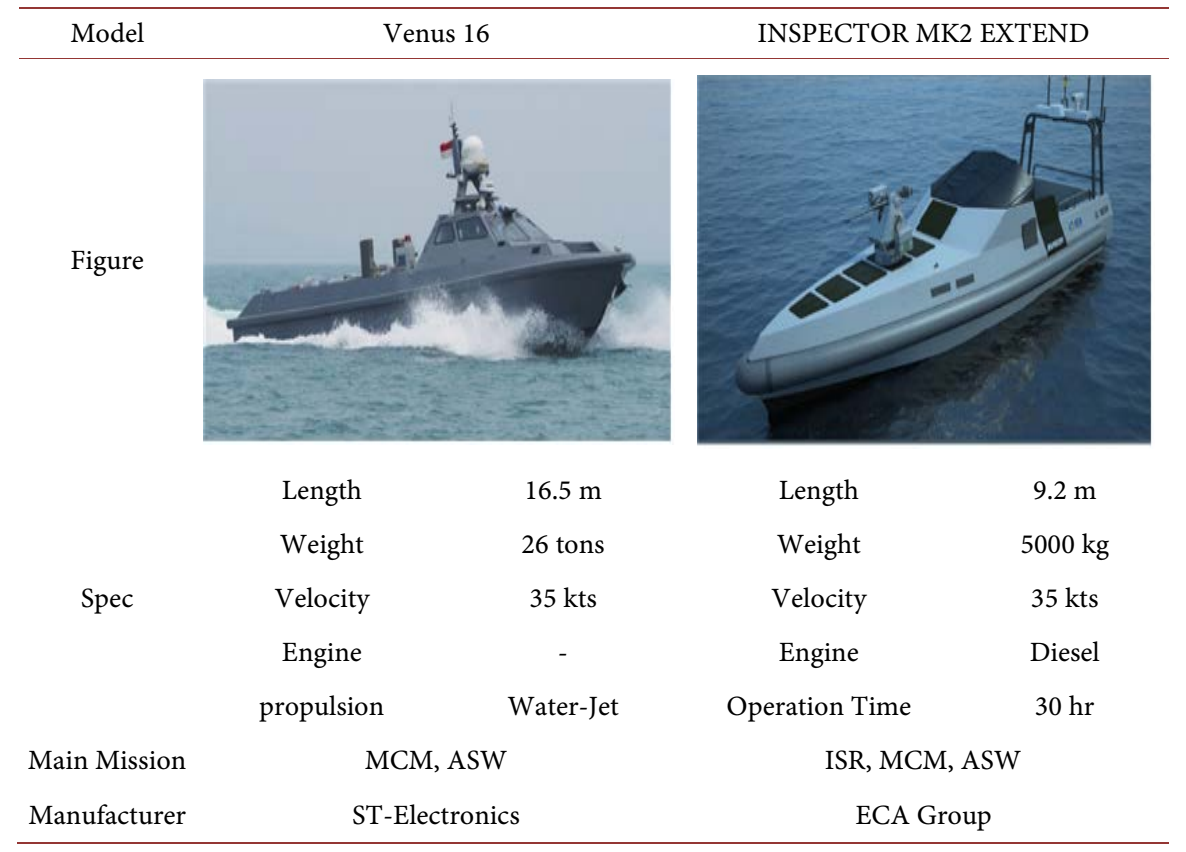


- Venus 16 is heavily armed, as opposed to Vigilant. It can also be used as manned platform, if necessary. Due to its modular construction, the hull can be lengthened and more fuel and weapons can be carried. Both are remotely operated.

\section{Analysis}

In case of US, a research level of the USV technology has been advanced significantly but most countries still lack technology to commercialize it [25]. In this study, the technology fields to be suggested through our analysis are largely autonomous system, collision avoidance, launching and recovery, weapon operation and common infrastructure technology for operation. In addition, to improve operability, it is important to upgrade the onboard equipment and to standardize the interface technology and modularization among the equipment. The USVs can be categorized by the size, fuel and operation range. Those determine the endurance of the USVs, which can be very important for reconnaissance mission. The onboard sensors determine the type of missions that the USVs can perform. The autonomy level also determines the USVs flexibility in terms of when the remote signals are lost or when the situation changes too rapidly for the remotely situated human operators can handle. In this regards, Table 6 shows the important design factors closely related to the required performance in USV development.

\section{Conclusions}

In this study, we derived factors and functions to be considered in the USV design through analyzing development cases of USV in major countries. The demand of USVs which can be autonomously operated without the operator intervention has been increasing dramatically. The growing interests lie in the facts that those USVs can be manufactured at much lower costs, and can be operated without the onboard human operators, while can be sent to the hostile or quite dangerous areas without the fear of losing human lives. The utilization and the deployment of such vessels will continue to grow in the future and the future will show the vessels with much higher autonomy levels. In such cases, the USVs can be operated at a much longer time without the intervention of human operators, which can fundamentally change the way the maritime warfare has been conducted. Additionally, the most important trend is the intelligence and autonomy levels of the USVs. With the advent of the AI (artificial intelligence, i.e.,

Table 6. Important design factors for developing USV.

\begin{tabular}{lll}
\hline & Design Factors & \\
\hline$\bullet$ Operation Time & $\bullet$ Operation Velocity \\
$\bullet$ Autonomous System & $\bullet$ Mission Range \\
$\bullet$ Fuel & $\bullet$ Size (Length, Width, Weight) \\
$\bullet$ Communication & $\bullet$ Equipment (Weapon, Sensor, etc.) \\
$\bullet$ Cost & $\bullet$ Payload Capacity \\
\hline
\end{tabular}


deep learning), previously impossible task such as recognizing enemy vessels through the camera images can be automated. In the future, the capability of the USVs will be highly dependent on the technology levels of AI and the autonomy along with the types of onboard sensing devices.

\section{Acknowledgements}

This work was supported by the Agency for Defense Development (ADD) under the Contract No. UD160008DD. The authors wish to express sincere gratitude for the financial support.

\section{References}

[1] Junglak, C. (2014) Trends in Military Unmanned Surface Vehicle. The Society of Naval Architects of Korea, 51, 3-8.

[2] Kim, T., Lee, Y. and Hyun, T. (2015) System Design of an Unmanned Surface Vehicle for Autonomous Navigation Research. Proceedings of the IEEK Conference, 897-900.

[3] Kim, S. (2014) Research Trends in Military Unmanned Vehicle. The Society of Naval Architects of Korea, 51, 2.

[4] Domenico, P., Venticinque, S. and Aversa, R. (2013) Autonomic Agents for Real Time UAV Mission Planning. 10th International Conference on Ubiquitous Intelligence and Computing and 10th International Conference on Autonomic and Trusted Computing, Vietri sul Mere, 18-21 December 2013, 410-415.

[5] Tan Yew, T., Chitre, M. and Vadakkepat, P. (2010) Hierarchical Agent-Based Command and Control System for Autonomous Underwater Vehicles. AIS.

[6] Lee, H. and Zeigler, B.P. (2010) SES-Based Ontological Process for High Level Information Fusion. Proceedings of the 2010 Spring Simulation Multiconference, Orlando, 11-15 April 2010, Article No. 129. https://doi.org/10.1145/1878537.1878672

[7] Farid, K. (2013) Towards a Unified Framework for Uas Autonomy and Technology Readiness Assessment (atra). Autonomous Control Systems and Vehicles. Springer, 55-71. https://doi.org/10.1007/978-4-431-54276-6_4

[8] Sebastian, C., Kriegel, M. and Schulte, A. (2013) UAV Capability Management Using Agent Supervisory Control. AIAA Infotech Aerospace Conference 2013, Boston.

[9] Glotzbach, T., Schneider, M. and Otto, P. (2008) Multi System Mission Control for Teams of Unmanned Marine Vehicles-Software Structure for Online Replanning of Mission Plans. Conference Proceedings of the 7 th International Conference on Computer Applications and Information Technology in the Maritime Industries, Belgium, 21-23 April 2008.

[10] Ergezer, H. and Leblebicioglu, K. (2013) Path Planning for UAVs for Maximum Information Collection. IEEE Transactions on Aerospace and Electronic Systems, 49, 502-520. https://doi.org/10.1109/TAES.2013.6404117

[11] Li, D., et al. (2016) Research on Intelligence, Surveillance and Reconnaissance Mission Planning Model and Method for Naval Fleet. Control and Decision Conference, Yinchuan, 28-30 May 2016, 2419-2424. https://doi.org/10.1109/ccdc.2016.7531391

[12] Yao, H., et al. (2016) Research on Situation Awareness Based on Ontology for UUV. 2016 IEEE International Conference on Mechatronics and Automation, Harbin, 7-10 August 2016, 2500-2506. https://doi.org/10.1109/icma.2016.7558959 
[13] Cui, K., Yang, Z. and Sun, W. (2015) The Collaborative Autonomy and Control Framework for Unmanned Surface Vehicle. 2015 Ninth International Conference on Frontier of Computer Science and Technology, Dalian, 26-28 August 2015, 242247. https://doi.org/10.1109/FCST.2015.53

[14] Shin, J., Kwak, D.J., Lee, Y., Lee, J., Joo, S. and Yun, S.J. (2015) System Identification and Control of Unmanned Surface Vessel for Autonomous Navigation. The Korean Society of Mechanical Engineers, 41-42.

[15] White, A. and Williams, H. (2016) Anaconda USV Development Progresses. http://www.janes.com/article/62848/anaconda-usv-development-progresses

[16] Littlefield, S. Anti-Submarine Warfare (ASW) Continuous Trail Unmanned Vessel (ACTUV).

http://www.darpa.mil/program/anti-submarine-warfare-continuous-trail-unmanne d-vessel

[17] EMEA Fleet-Class Common Unmanned Surface Vessel (CUSV) United States of America.

http://www.naval-technology.com/projects/fleet-class-common-unmanned-surfacevessel-cusv

[18] Marine News, Tech File: USV Delivered to U.S. Navy for LCS. https://www.marinelink.com/news/delivered-file-tech327991

[19] ElianaFishler, A KATANA model, IAI's Unmanned Marine System, Is Presented at Euronaval. http://www.iai.co.il/2013/36782-46150-en/MediaRoom.aspx

[20] Williams, H., Rafael Launches Spike Missiles from Protector USV. http://www.janes.com/article/68558/rafael-launches-spike-missiles-from-protector$\underline{\text { usv }}$

[21] Barbara Opall-Rome, Israel's Elbit Unveils USV for Anti-Sub, Anti-Mine Missions. http://www.defensenews.com/story/defense/naval/2016/02/08/israels-elbit-unveilsusv-anti-sub-anti-mine-missions/80001006

[22] Lundquist, E.H., Zycraft Independent Unmanned Surface Vehicle (IUSV). http://www.defensemedianetwork.com/stories/zycraft-independent-unmanned-surf ace-vehicle-iusv

[23] Catama, M., Singapore Unveils Venus 16 Unmanned Surface Vehicle. http://www.aseanmildef.com/2015/11/singapore-unveils-venus-16-unmanned.html

[24] RICHARD SCOTT, Automation Keeps Men off the Minefield. http://www.janes.com/article/68067/automation-keeps-men-off-the-minefield-idex $\underline{17 \mathrm{~d} 4}$

[25] Suh, J., Kim, D. and Lee, H. (2011) Development Trend of Autonomous Unmanned Underwater Vehicle Navigation Technology. Journal of Control, Robotics and Systems, 17, 36-46. 
Submit or recommend next manuscript to SCIRP and we will provide best service for you:

Accepting pre-submission inquiries through Email, Facebook, LinkedIn, Twitter, etc. A wide selection of journals (inclusive of 9 subjects, more than 200 journals)

Providing 24-hour high-quality service

User-friendly online submission system

Fair and swift peer-review system

Efficient typesetting and proofreading procedure

Display of the result of downloads and visits, as well as the number of cited articles Maximum dissemination of your research work

Submit your manuscript at: http://papersubmission.scirp.org/

Or contact jec@scirp.org 